\title{
User Experience Penggunaan Google Classroom dan Quizizz Dalam Pembelajaran Blended Learning Program Studi Sistem Komputer
}

\author{
Anak Agung Gde Ekayana \\ Sistem komputer, STMIK STIKOM Indonesia, Indonesia \\ gungekayana@stiki-indonesia.ac.id
}

\begin{abstract}
Abstrak
Penelitian ini bertujuan mengevaluasi User Experience (UX) dalam menggunakan Google Classroom (GC) dan Quizizz dalam proses belajaran Blended Learning. Pembelajaran dengan sistem daring saat ini lebih banyak menggunakan Learning Management System (LMS) GC sebagai tempat interaksi antara pengajar dengan peserta didik dan menggunakan Quizizz sebagai tools untuk melakukan tes secara online. Penggunaan LMS dan aplikasi online saat ini masiv digunakan, untuk itu perlu adanya evaluasi untuk mengukur tingkat UX penggunaan LMS dalam proses pembelajaran. Metode yang digunakan dalam penelitian ini menggunakan metode $A$ Technique for User eXperience Evaluation in e-Learning (TUXEL) Versi 2.0. Metode TUXEL merupakan teknik yang dapat digunakan untuk mengevaluasi kegunaan dan pengalaman pengguna. Hasil penelitian terbagi menjadi 3 aspek yaitu general usability, pedagogical usability dan UX, pada aspek general usability ditemukan 10 permasalahan pada kategori user login. 16 permasalahan didapatkan pada aspek pedagogical usability. Aspek UX menghasilkan 3 kategori yaitu kreatif, inovasi dan belum sesuai ekspektasi. Penggunaan Quizz dari hasil kuesioner menghasilkan Baik/Setuju digunakan dalam proses belajaran, karena lebih interaktif dan menarik. Simpulan yang dapat dirumuskan adalah LMS GC walaupun masih ada kekurangan pada aspek general usability dan pedagogical usability, namun memiliki nilai kreatif dan inovatif kepada pengguna dalam proses pembelajaran.
\end{abstract}

Kata kunci: blended learning, google classroom, quizizz, user experience.

Dikirim: 03 April 2021

Direvisi: 03 Mei 2021

Diterima: 25 Mei 2021

Identitas Artikel:

Ekayana, A. A. G. (2021). User Experience penggunaan Google Classroom dan Quizizz dalam Pembelajaran Blended Learning Program Studi Sistem komputer. Jurnal Ilmи Pendidikan (JIP) STKIP Kusuma Negara, 13(1), 23-34.

\section{PENDAHULUAN}

Pada era digital yang mendukung penggunaan teknologi membuat perubahan yang cukup signifikan pada lingkungan tempat tinggal, perkantoran, pelayanan masyarakat, perekonomian dan hiburan. Hal ini menandai bahwa dunia memasuki era revolusi industri 4.0 (Nurfalah, 2019). Perubahan yang terjadi wajib mendukung penghematan sumber daya, baik secara fisik, energi dan material. Pada tahun 2021 yang sedang berjalan ini, perubahan sangat dirasa cukup besar, salah satunya perubahan kegiatan pembelajaran. Perubahan yang positif pada lini pembelajaran wajib mendukung prinsip efisien, efektif dan mengarah pada hasil yang pasti. Efektivitas dalam pembelajaran sangat penting, karena berpengaruh pada proses dan hasil belajar (Fauzan \& Arifin, 2019). Pembelajaran yang masih menggunakan cara-cara lama/konvensional menyebabkan banyak kendala dan kesenjangan yang 
terjadi (Ekayana \& Rakasiwi, 2019). Permasalahan itu terus muncul jika pengajar/dosen tidak melakukan suatu perubahan yang lebih optimal untuk memecahkan masalah tersebut. Mahasiswa dalam proses belajar memerlukan motivasi untuk mampu mengikuti dan mempunyai keinginan untuk belajar (Nirfayanti \& Nurbaeti, 2019). Masa pandemi covid-19 telah merubah proses pembelajaran yang dulunya tatap muka di dalam kelas berganti menjadi pembelajaran daring/online. Pembelajaran daring membuat para pendidik wajib mengetahui dan memahami teknologi, agar proses pembelajaran bisa tetap dilaksanakan dengan baik. Pemanfaatan teknologi menjadi penting pada era saat ini, dimana sebagain besar sektor masyarakat sudah menerapkan teknologi, salah satunya dunia pendidikan. Dampak yang terjadi adalah pergeseran proses pembelajaran konvensional ke arah pendidikan yang lebih terbuka dengan memanfaatkan teknologi (e-learning) (Nurfalah, 2019).

Pembelajaran dengan sistem online memerlukan suatu wadah untuk pendidik dapat berinterasi dengan peserta didik, layaknya proses tatap muka didalam kelas, sehingga dosen dengan mahasiswa dapat berbagi materi, tugas dan interaksi pembelajaran. Pemanfaatan e-learning menjadi solusi saat proses pembelajaran dilakukan secara daring, dengan memanfaatkan LMS (Siregar, Rokhmawati \& Azzahra, 2019) seperti GC untuk interaksi materi, tugas, dan live session pembelajaran dan Quizizz sebagai tools pendukung dalam melaksanakan ujian atau tes secara online. Pembelajaran dengan sistem daring selain menggunakan LMS dan aplikasi pendukung lainnya, juga diperlukan metode yang tepat untuk dapat mengimplementasikan pembelajaran jarak jauh melalui penerapa teknologi, metode yang tepat untuk proses pembelajaran jarak jauh adalah Blended Learning. Blended learning atau biasa disebut pembelajaran campuran (Maulida, 2020) saat ini sangat trend di lakukan, baik berupa workshop, seminar maupun kegiatan langsung di dalam kelas. Blended learning mendukung kombinasi dari materi pembelajaran antara pembelajaran konvensional dengan pembelajaran daring (Wicaksono \& Rachmadyanti, 2016), gaya pembelajaran, komunikasi dan manajemen dari proses pembelajaran. Blended learning dalam pelaksanaannya wajib didukung teknologi internet (Suyanto, 2020) dan beberapa tools yang relevan dalam melakukan aktivitas pembelajaran, salah satu tools yang dapat digunakan yaitu GC (Ruang Kelas Google) sebagai wadah untuk mengelola proses pembelajaran, dari informasi, komunikasi, tugas-tugas, materi dan penilaian yang dilakukan selama proses pembelajaran, dan tools Quizizz merupakan aplikasi berbasis web untuk menyelenggarakan evaluasi selama proses pembelajaran, segala tes kepada mahasiswa dapat dilakukan secara online dan dapat dilakukan kapanpun dan dimanapun.

UX merupakan suatu pengalaman yang dirasakan seseorang sebagai pengguna dalam menggunakan suatu teknologi tertentu, baik sebuah aplikasi, internet, dan sistem, bisa digolongkan sebuah pandangan dan tanggapan seseorang berdasarkan pengguna dan atau hal yang diantisipasi pengguna dari suatu produk, sistem, atau layanan (ISO 9241-210). Beberapa orang menyebut bahwa UX merupakan sebuah platfom yang mampu menampung kepentingan semua stakeholder (Munthe, Brata \& Fanani, 2018). Perkembangan teknologi yang semakin pesat yang mencakup semua sektor-sektor vital masyarakat, termasuk sektor pendidikan melahirkan istilah-istilah yang mendukung penerapan teknologi salah satunya e-leaning. Penggunaan suatu aplikasi dari penerapan teknologi informasi dan komunikasi 
perlu dilakukan analisis dan penelitian, karena jika UX saat penggunaan suatu aplikasi atau LMS buruk, maka dapat mempengaruhi sikap dan perilaku belajar peserta didik ketika menggunakan aplikasi atau LMS tersebut (Nurhayati, Az-zahra \& Herlambang, 2019; Pradana \& Harimurti, 2017). Permasalahan yang menjadi fokus pada penelitian ini yaitu melakukan evaluasi pengalaman pengguna terhadap pemanfaatan GC dan Quizizz ditinjau dari aspek masing-masing fitur yang ada, dari hasil penelitian sebelumnya yang relevan hanya sebatas memberikan tanggapan terkait penggunaan LMS tanpa ada penjelasan terkait fitur-fitur yang ada di dalam LMS, apakah sudah mendukung pengguna dalam proses pembelajaran atau sebaliknya. Sehingga penelitian ini memberikan hasil lebih detail terkait fitur-fitur yang menjadi pendukung didalam LMS untuk proses pembelajaran.

GC merupakan sebuah tools pembelajaran daring (Su'uga, Ismayati, Agung\& Rijanto, 2020) yang diciptakan oleh Google sebagai wadah dalam mendukung proses pembelajaran yang mampu untuk mengelola setiap materi, tugas-tugas, informasi dan penilaian. Penggunaan GC merupakan pengembangan dan perubahan dalam aktivitas pembelajaran, dengan GC mahasiswa dikelompokkan pada suatu kelas dengan kode sebagai kunci masuknya. GC memberikan penghematan dalam hal penugasan kepada mahasiswa yang mengedepankan paperless (mengurangi penggunaan kertas) (Tarida \& Indriyani, 2020), dengan menggunakan fitur tugas di GC, pengajar dapat membuat tempat-tempat untuk menampung tugas-tugas mahasiswa dan dilengkapi dengan informasi, jam, hari dan keterangan pengumpulan tugas.

Quizizz merupakan tools berbasis Web digunakan sebagai media melakukan evaluasi (tes maupun non tes) secara online (Setiyoningtyas \& Kasmui, 2020). Media Quizizz memungkinkan seorang dosen mengatur soal-soal yang diberikan kepada mahasiswa, soal-soal tes yang telah dibuat dapat dikerjakan secara live, penugasan hari tertentu dan uji coba. Tampilan tes yang diberikan dari media Quiziz lebih menarik dengan memadukan text, gambar, audio dan warna-warna yang dikombinasikan menjadi satu (Wahyudi, Rufiana \& Nurhidayah, 2020). Quizizz mendukung pembahasan dan penyampaian penjelasan soal-soal setelah soal selesai dikerjakan, ada juga fitur rangking, poin dan rekapan dalam bentuk excel yang dapat digunakan sebagai bahan penilaian mahasiswa.

\section{METODE PENELITIAN}

Metode yang diterapkan pada penelitian $U X$ menggunakan TUXEL 2.0 disebut juga inpection process. Metode TUXEL merupakan teknik yang digunakan untuk mengevaluasi kegunaan (usability) dan pengalaman (user experince) LMS (Nurhayati et al., 2019) berdasarkan sudut pandang user (mahasiswa). TUXEL dalam proses kerjanya menggunakan pengumpulan data berupa kuesioner dengan kode-kode khusus untuk mendapatkan data, yang selanjutnya dianalisis berdasarkan tahapan yang telah ditentukan. Metode TUXEL digunakan untuk menganalisis UX pada LMS GC dan aplikasi tes online Quizizz dari sudut pandang mahasiswa prodi sistem komputer. Analisi data menggunakan semantic differential scale dan Kuesioner yang telah dibuat dan disebar kepada mahasiswa sistem komputer yang berjumlah 50 orang mahasiswa.

Tahapan dari TUXEL adalah perencanaan, usability inspection, pedagogical inspection dan ux evaluation (Nakamura, Oliveira \& Conte, 2018). Penelitian yang 
baik tentunya dilakukan dengan terstruktur dengan tahapan-tahapan yang jelas, adapun tahapan pada penelitian ini diperlihatkan pada gambar berikut.

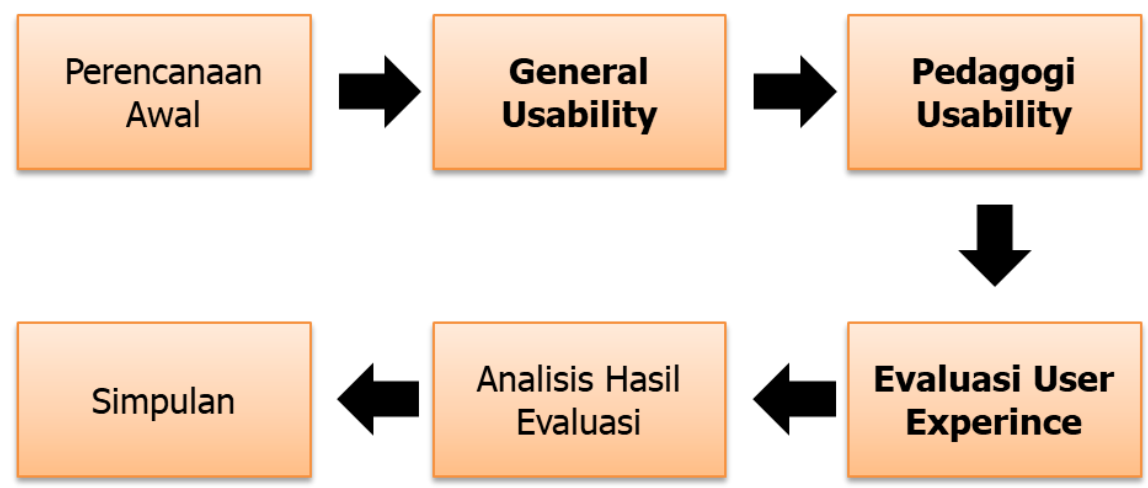

Gambar 1. Tahapan Penelitian UX

Pada tahap perencanaan dilakukan analisis awal untuk penelitian UX ini, adapun rencana yang dilakukan adalah menentukan banyaknya user yang digunakan dalam pengumpulan data, strategi penyebaran kuesioner kepada user agar lebih optimal, jumlah uraian yang ada pada kuesioner dan dimensi dari kuesioner yang mendukung pada penelitian UX. Pada penelitian UX digunakan pengumpulan data primer berupa penyebaran kuesioner kepada user, dengan digunakannya data primer harapannya hasil penelitian ini dapat digunakan untuk bahan kajian dan bukti proses pembelajaran yang relevan dalam penggunaan tool pendukung pembelajaran GC dan Quizizz. Penentuan dimensi atau kategori dilakukan pada tahapan perencanaan agar terlihat lebih jelas bagian dan ruang lingkup mana saja yang mendukung dalam evaluasi UX. Dimensi TUXEL yang diuraikan ke dalam kuesioner meliputi: General Usability, Pedagogical Usability, dan Evaluasi Pengalaman Pengguna.

Pada tahap perencanaan juga dilakukan langkah-langkah pengumpulan data berupa pemberikan penjabaran tugas (task definition) dan tabel ceklist (checklist matching). Tugas-tugas yang disusun diberikan kepada mahasiswa selaku inspektor, selanjutnya tugas yang dibuat digunakan untuk menganalisis GC dan Quizizz serta fitur yang terdapat didalam Learning Management System tersebut. Tugas-tugas yang dibuat diadopsi dari fitur-fitur yang ada pada TUXEL yaitu: (1) General interface, (2) user login, (3) Assigments, (4) Assesment. Pengumpulan data berupa tabel ceklist digunakan untuk mencocokan antar tugas yang diberikan dengan kategori yang ada pada metode TUXEL, selanjutnya menghasilkan Tabel 1 untuk tugas inspektor GC dan Quizizz.

Pada tahap Kegunaan Umum (General Usability) dilakukan untuk menganalisa fungsi kegunaan (usability) yang ada pada Learning Management System. Peneliti sudah menyiapkan tugas-tugas (tasks) yang diberikan kepada mahasiswa sebagai inspektor, ketika dalam pengerjaan tugas yang diberikan ditemukan ada masalah maka inspektor menuliskan permasalahan tersebut pada tabel pelaporan masalah, seperti contoh yang terdapat pada Tabel 2. Pada tabel pelaporan masalah, inspektor mencatat apakah setiap masalah terjadi hanya sekali atau berulang pada seluruh Learning Management System. 
Tabel 1. Task Inspektor TUXEL

\begin{tabular}{|c|c|c|}
\hline No & Tugas (Task) & Kategori \\
\hline 1 & $\begin{array}{l}\text { Akses GC dan Quizizz, lalu masuk ke akun } \\
\text { (sign in) kalian masing-masng, jika belum } \\
\text { mempunyai akun, segera lakukan } \\
\text { pendaftaran (sign up) }\end{array}$ & Login, General Interface \\
\hline 2 & $\begin{array}{l}\text { Join ke dalam kelas pada GC yang sudah } \\
\text { disiapkan (kode: } 75 \text { uwsbz), masukan kode } \\
\text { pada Quizizz }\end{array}$ & Login, General Interface \\
\hline 3 & $\begin{array}{l}\text { Perhatikan dan pelajari setiap materi yang } \\
\text { terdapat pada halaman kelas di GC dan } \\
\text { Quizizz }\end{array}$ & General Interface, Task \\
\hline 4 & $\begin{array}{l}\text { Tulislah komentar terkait materi yang } \\
\text { sudah kalian pelajari dikolom komentar. }\end{array}$ & General Interface \\
\hline 5 & $\begin{array}{l}\text { Lakukan pengumpulan tugas sesuai } \\
\text { deskripsi yang ada di kelas GC (membuat } \\
\text { proposal) dan kerjakan tes pada Quizizz }\end{array}$ & $\begin{array}{l}\text { General Interface, Task, } \\
\text { Assessment }\end{array}$ \\
\hline 6 & $\begin{array}{l}\text { Kerjakan soal-soal latihan pada Quizizz } \\
\text { (Metodologi penelitian) }\end{array}$ & $\begin{array}{l}\text { General Interface, } \\
\text { Assessment }\end{array}$ \\
\hline 7 & $\begin{array}{l}\text { Log out (keluar) dari akun kalian masing- } \\
\text { masing }\end{array}$ & Login, General Interface \\
\hline
\end{tabular}

Pada Pedagogical Usability menganalisis kegunaan (usability) fitur-fitur pembelajaran yang ada pada LMS, fitur-fitur yang dimaksud adalah segala jenis daya upaya yang ada pada LMS untuk proses pembelajaran, seperti: fitur diskusi, fitur materi, fitur link dan file, fitur upload dan download, dan lain-lain. Segala fitur tersebut memungkinkan pengguna LMS untuk dapat meraih kesuksesan belajar. Pada tahap ini segala fitur yang disediakan dilakukan analisis fungsinya masingmasing dan harus dapat memfasilitasi materi pembeajaran yang disampaikan kepada peserta didik. Tahap inspeksi Pedagogical Usability terbagi menjadi empat kelompok antara lain yaitu, Help dan Documentation, LMS Learnability, Learning Through the LMS, dan LMS Flexibility. Pada kelompok Help dan Documentation (Bantuan dan dokumentasi) berarti berkaitan dengan fitur-fitur yang menyediakan bantuan dan petunjuk penggunaan LMS.

Tabel 2. Tabel Pelaporan Masalah

\begin{tabular}{cllll}
\hline $\begin{array}{c}\text { ID } \\
\text { Item }\end{array}$ & \multicolumn{1}{c}{ Tugas } & \multicolumn{1}{c}{ Permasalahan } & $\begin{array}{l}\text { Apakah } \\
\text { masalah } \\
\text { terjadi } ?\end{array}$ & $\begin{array}{l}\text { Dibagian mana } \\
\text { masalah terjadi } \\
\text { dan berulang ? }\end{array}$ \\
\hline N1 & $\begin{array}{l}\text { Bergabung } \\
\text { ke dalam } \\
\text { kelas }\end{array}$ & $\begin{array}{l}\text { Kesulitan mencari } \\
\text { tombol join atau gabung, } \\
\text { tidak adanya petunjuk } \\
\text { awal }\end{array}$ & $\begin{array}{l}\text { Ya, pada } \\
\text { beberapa } \\
\text { kelas }\end{array}$ & $\begin{array}{l}\text { Saat masuk ke } \\
\text { group kelas }\end{array}$ \\
\hline
\end{tabular}

LMS Learnability (kemudahan dipelajari) berkaitan dengan setiap fitur yang ada di LMS dapat dipelajari dengan baik. Learning Through the LMS (belajar dengan LMS) berkaitan dengan sejauh mana LMS dapat membantu peserta didik untuk belajar memahami materi pembelajaran. LMS Flexibility (LMS yang 
Fleksibilitas) berakaitan dengan kemerdekaan para peserta didik untuk memilih dan mengakses materi pembelajaran yang ada pada LMS.

Pada tahapan Evaluasi User Experince merupakan tahapan yang bertujuan mengevaluasi pengalaman peserta didik dari penggunaan LMS dengan menggunakan teknik semantic differential scale. Pengumpulan data yang dilakukan menggunakan kuesioner dengan menggunakan teknik User Experince Questionnaire (UEQ), kuesioner yang dirancang menggunakan enam parameter dari TUXEL yang selanjutnya dijabarkan lagi menjadi dua belas item, skala yang digunakan menggunakan dua pasang kata sifat, seperti Tabel 3. Tujuan dari evaluasi ini yaitu menganalisis sejauhmana persepsi dan pengalaman peserta didik ketika menggunakan LMS.

Tabel 3. Tabel Parameter UX

\begin{tabular}{|c|c|c|}
\hline No & Parameter & Kata sifat \\
\hline 1 & $\begin{array}{l}\text { Daya Tarik } \\
\text { (Attractiveness) }\end{array}$ & $\begin{array}{l}\text { Tidak disukai/Tidak nyaman digunakan/Menyenangkan } \\
\text { /Nyaman digunakan }\end{array}$ \\
\hline 2 & $\begin{array}{l}\text { Ketepatan } \\
\text { (Dependability) }\end{array}$ & $\begin{array}{l}\text { Tidak sesuai ekspektasi/sesuai ekspektasi/menghambat / } \\
\text { mendukung }\end{array}$ \\
\hline 3 & $\begin{array}{l}\text { Efisiensi } \\
\text { (Efficiency) }\end{array}$ & Tidak efisien/Efisien/Tidak Praktis/Praktis \\
\hline 4 & $\begin{array}{l}\text { Kebaruan } \\
\text { (Novelty) }\end{array}$ & Konvensional/Kreatif/Tidak Kreatif/Kreatif \\
\hline 5 & $\begin{array}{l}\text { Kejelasan } \\
\text { (Perspiculty) }\end{array}$ & Sulit/Mudah/Membingungkan/Sangat Jelas \\
\hline 6 & $\begin{array}{l}\text { Stimulasi } \\
\text { (Stimulation) }\end{array}$ & Tidak Menarik/Menarik/Tidak Memotivasi/Memotivasi \\
\hline
\end{tabular}

Mahasiswa selaku inspektor dapat memberikan pendapat mereka terhadap penggunaan LMS dengan memilih pernyataan yang paling sesuai dengan pengalaman yang mereka dapatkan saat menggunakan e-learning. Pada bagian akhir kuesioner, inspektor diberikan ruang untuk menuliskan kritik dan saran terhadap penggunaan LMS. Analisis data pada metode TUXEL mengacu pada tabel 2, dimana data yang didapatkan dari pengguna, dikelompokan menjadi sebuah tabel, dan data pada tabel tersebut berisikan ID Item terkait permasalahan yang muncul selama penggunaan LMS. Selanjutnya data pada tabel akan dilakukan analisis menggunakan sematic differential scale seperti yang terlihat pada Tabel 3, tujuan dari analisis ini adalah melakukan evaluasi terkait persepsi dari pengguna. Hasil analisis dirubah menjadi bentuk grafik, seperti Gambar 2, untuk menunjukan rentang dari hasil persepsi pengguna dalam penggunakan LMS.

\section{HASIL PENELITIAN}

Pada analisis General Usability, didapatkan hasil, yaitu pada bagian Login LMS dengan ID LF2, adapun masalah yang ditemukan pada bagian login kurang terdapatnya pop up awal atau isian yang wajib diisi kepada user yang baru memulai LMS, sehingga perlu waktu lebih lama untuk mencari dan menemukan fitur login yang dimaksud (LF2). Pada bagian General Interface, sepuluh responden menemukan beberapa permasalah yang perlu perhatian pada LMS yang digunakan 
dengan kode yang berbeda-beda pada ID N6, N2, L4, LC3 dan N1. Penjelasan dari masalah yang ditemui sebagai berikut (N6) kurang adanya kolom pada LMS untuk mencari informasi lebih akurat dan cepat; (N2) kurangnya navigasi atau petunjuk kepada user kebagian mana harus melangkah; (L4) beberapa tombol, label dan icon yang ada pada LMS memiliki fungsi yang kurang jelas kepada responden; (LC3) belum ada tombol exit cepat pada sistem LMS yang dapat digunakan kapan saja; (N1) fitur navigasi pada LMS sulit untuk diingat, sehingga responden sering menekan tombol yang salah.

Pada bagian Assigment ditemukan beberapa permasalahan dari responden yaitu pada ID LF1 dan LF4, adapun penjabaran dari permasalahan tersebut antara lain: (LF1) pada bagian pengiriman tugas/file kurang adanya notifikasi atau pesan yang menandakan bahwa tugas sudah terkirim dengan benar atau tidak, (LF4) tidak adanya konfirmasi balik terkait isian yang benar diisi atau tidak diisi.Pada bagian Assessment, ditemukan dua masalah yang dari responden yaitu pada ID IF1 dan IF2. Permasalahan yang ditemukan pada bagain ini dijelaskan sebagai berikut: (IF1) kurangnya feedback dari LMS jika terjadi kesalahan dari pihak user, (IF2) tidak adanya pesan yang muncul saat responden selesai mengerjakan task pada classroom, terkesan tidak ada apa-apa yang terjadi.

\section{Pedagogical Usability}

Pada Analisis Pedagogical Usability yang menjadi fokus pada $U X$ selanjutnya yaitu aspek pedagogical Usability, dari kuesioner yang telah disebar, ditemukan beberapa permasalahan yang cukup krusial terkait penggunaan LMS, adapun jabaran dari temuan tersebut antara lain: pada kategori Help dan Documentation, terdapat tiga item yang menjadi kendala bagi user yaitu ID HD3, HD2, dan HD1. Kendala pada ID HD1 pada LMS GC kurang adanya bantuan yang dapat digunakan oleh user dalam menggunakan LMS, baik secara online atau konvensional; kendala pada ID HD2 tidak adanya penjelasan yang akurat terkait bantuan dalam menggunakan LMS, dan sulitnya mencari bantuan dengan mudah; kendala pada ID HD3 kurang representatif arahan yang ada pada LMS sehingga user masih mengalami kebingunan saat menggunakan LMS. Pada kategori Help dan Documentation yang disediakan oleh TUXEL, semua ID terdapat kendala bagi user/mahasiswa, sehingga kedepannya saat menggunakan LMS GC perlu diberikan tutorial dan panduan penggunaan LMS, harapannya kendala yang seperti penjelasan diatas tidak terjadi lagi.

Pada ketegori Learnability, responden mendapatkan dua permasalahan dengan ID L1 dan L3, permasalahan yang ditemukan pada ID L1 bahwa LMS GC kurang intuitif dalam proses penggunaannya, sehingga user yang menggunakan LMS tersebut sering merasa kesulitan; permasalahan pada ID L3 dijelaskan bahwa user atau responden kurang mampu menyelesaikan tugas dengan mandiri, dalam arti lainnya saat menggunakan LMS user perlu bantuan teman atau orang lain untuk membantu menggunakan LMS untuk menyelesaikan tugas-tugas. Pada kategori Learning through the LMS, dikategori ini responden menemukan pemasalahan pada beberapa ID, ada lima item yang terdapat pada kategori yaitu ID (OO2) pada LMS yang digunakan user tidak dapat memantau kemanjuan atau perkembangan kemampuan diri terhadap materi yang dikerjakan; pada ID (CL1) LMS yang digunakan tidak ada fitur belajar secara berkelompok, hanya belajar secara mandiri saja, ID (CL2) pada LMS tidak terdapat fitur untuk memudahkan antar user atau 
user dengan dosen untuk berkomunikasi; ID (CL3) pada LMS GC, masing-masing user hanya dapat melihat pekerjaannya sendiri, tidak dapat melihat pekerjaan teman lain baik tugas, nila atau peringkat; ID (CL5) pada LMS tidak ada fitur untuk berlatih/ragu-ragu dalam menjawab pertanyaan, sehingga jawaban dari user harus yang sudah dipikirkan dan sudah dikoreksi sebelumnya.

Pada kategori LMS Flexibility, oleh responden ditemukan enam ID yang menjadi permasalahan, adapaun penjelasan dari masing-masing masalah tersebut, antara lain: ID (AI1) pada item ini LMS yang digunakan tidak dapat melakukan evaluasi sehingga perlu bantuan aplikasi lain untuk melakukan evaluasi, dimana pada penelitian ini menggunakan Quizizz sebagai tools evaluasi dari kseselurhan materi yang disedikan; ID (P1) pada LMS dan tool evaluasi tidak ada fitur untuk mengatur tampilan antar muka, sehingga dari awal user interface ditetapkan oleh pihak LMS; ID (P2) pada LMS yang digunakan tidak ada fitur atau menu untuk meningkatkan kreativitas responden; ID (FL1) responden dalam menggunakan LMS diwajibkan bergabung ke dalam kelas dengan menggunakan kode unik, hal ini menyebabkan responden tidak bisa memilih materi-materi yang disesuaikan dengan kemampuan responden; ID (FL2) responden dalam pengalamannya menggunakan LMS, sering ditemui pertanyaan terkait tidak adanya konsultasi dengan dosen dalam menyelesaikan tugas atau materi yang membinggungkan; ID (F13) pada LMS tidak adanya umpan balik yang diperoleh dari luar, hanya berkecimpung di dalam kelas tersebut, sehingga responden hanya berkomunikasi dua arah saja (user ke dosen, atau dosen ke user).

\section{User Experience}

Tahapan yang terakhir pada metode TUXEL yaitu dilakukannya pemberikan angket terkait pengalaman user dalam menggunakan LMS, $U X$ dilakukan dengan memberikan angket yang terdiri dari 12 item pernyataan kepada 20 orang responden. Angket yang disusun menggunakan range -3 sampai 3, adapun kriteria dalam angket UX memiliki beberapa kode yaitu (1) membingungkan; (2) tidak memenuhi harapan; (3) Menyenangkan; (4) inovatif. Range yang digunakan memiliki keterangan dari nilai media hasil angket yaitu 3 artinya inovatif, 2 artinya menyenangkan, 1 artinya tidak efisien dan 0 artinya tidak memenuhi ekspektasi. Grafik dari pengalaman pengguna dalam menggunakan LMS yang terdiri dari 20 orang responden ditampilkan pada Gambar 2.

\section{PEMBAHASAN}

Hasil evaluasi dari UX GC dan Quizizz menunjukan bahwa tidak semua peserta didik mampu menggunakan tools dengan baik, tingkat pengetahuan dan psikomotorik yang berbeda mengakibatkan permasalahan muncul saat penggunakan LMS, hasil penelitian ini sudah mengacu pada indikator metode TUXEL, dimana setiap fitur yang ada pada LMS diberikan notasi dan keterangan, jika terdapat permasalahan dari pengguna terkait fitur di dalam LMS, maka akan lebih mudah untuk mengambil solusi yang diberikan. Standar penelitian untuk hasil penelitian UX berdasarkan referensi masih tergolong sedikit, sehingga hasil pembahasan mengkrucut pada tanggapan dari pengguna terhadap fitur dan menu yang ada pada LMS. Temuan dari penelitian ini yaitu tidak semua pengguna GC dan Quizizz dapat mengunakan tools tersebut dengan baik, (Siregar et al., 2019) 
tingkat pengetahuan yang berbeda menjadi salah satu penyebabnya, dan LMS yang sedang digunakan saat ini belum sepenuhnya memberi solusi atau notifikasi jika terjadi kekeliruan dalam penggunaannya. Hasil penelitian sebelumnya belum ada pengevaluasi 2 tools yang saling berkaitan, hanya membanding 2 tools dengan fungsi yang sama, sehingga pada penelitian ini memberikan hasil pengalaman pengguna dalam menggunakan tools pembelajaran yang saling berkaitan satu dengan lainnya, dimana setiap proses pembelajaran ada evaluasi yang wajib diberikan, sehingga tool LMS sebagai proses pembelajaran dan tools Quizizz sebagai tempat evaluasi pembelajan dapat digunakan secara optimal oleh pengguna dalam pembelajaran. Berikut ini penjabaran pembahasan terkait hasil penelitian, dimana pembahasan lebih menjabarkan secara langsung pengalaman pengguna berdasarkan aspek yang ada pada metode TUXEL.

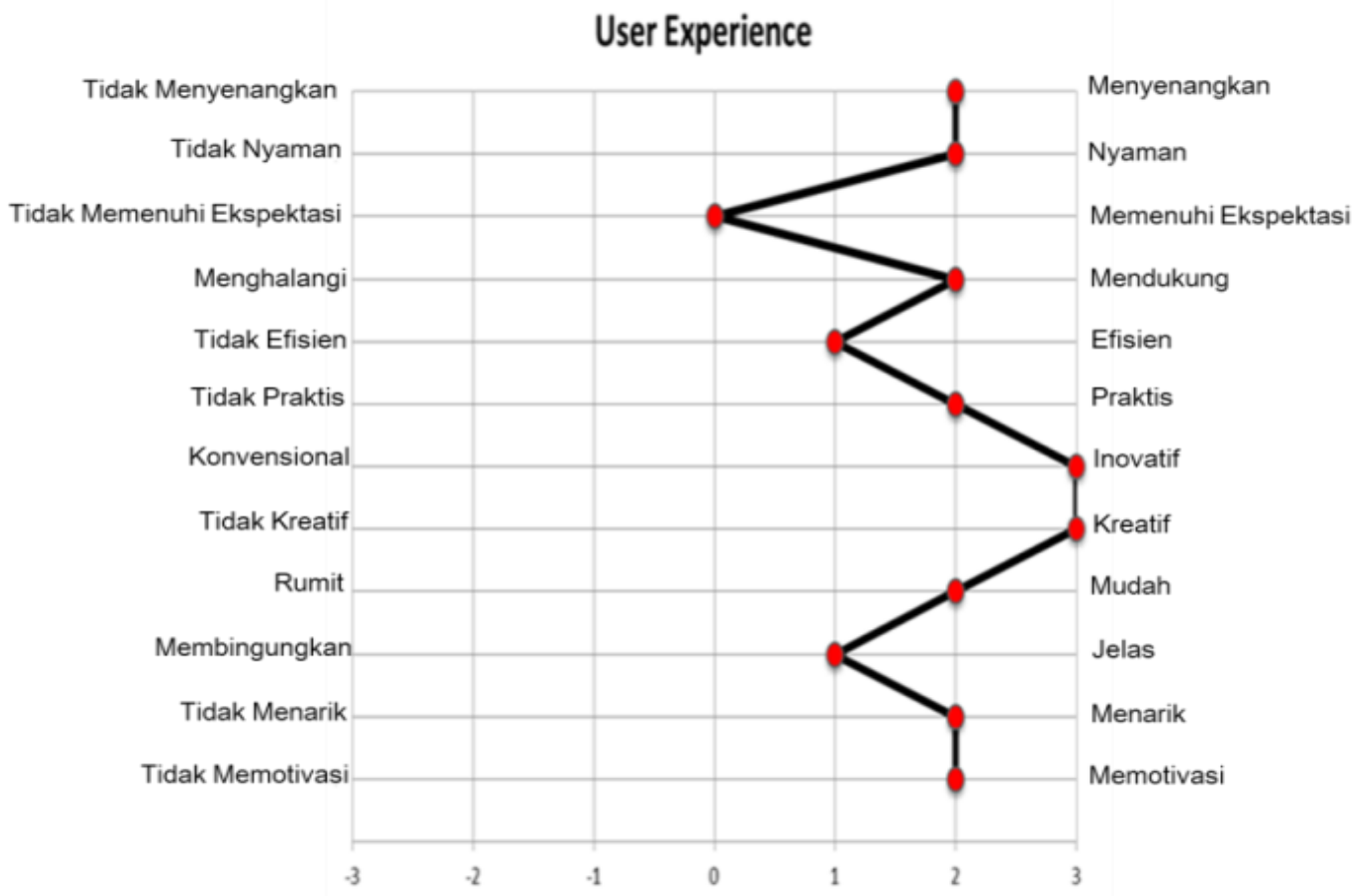

Gambar 2. Tampilan Grafik Pengalaman Pengguna

Pada aspek general usability penggunaan LMS GC ditemukan 10 item yang menjadi permasalahan, pada ketegori user login, ditemukan 1 item yang menjadi masalah yaitu fitur login yang tidak tertampil dengan jelas, bagi user yang baru mengunakan sangat merasa kebingungan untuk mencari tombol login pada LMS GC, kedepannya perlu adanya pesan atau notifikasi sebagai petunjuk bagi user yang baru mengunakan LMS. Kategori yang terdapat pada aspek general usability meliputi: user login, general interface, Assignment, dan assessment masing-masing dari kategori terdapat beberapa pemasalahan yang ditemukan oleh mahasiswa, masalah-masalah tersebut menjadi perhatian bagi mahasiswa yang baru pertama kali menggunakan LMS GC, menurut kaedah usability dikatakan bahwa suatu sistem atau aplikasi yang dibuat harus mampu memberikan keefektifan dan keefisienan saat digunakan, tentunya dengan kemampuan tersebut seyogyanya sistem mampu membantu penggunaan untuk mencapai tujuan yang diharapkan. 
Pada aspek pedagogical usability dengan menggunakan metode TUXEL didapatkan ada 16 item permasalahan yang dirasakan oleh responden, permasalah yang terjadi letaknya tersebar pada kategori yang ada pada aspek pedagogical usability, diantaranya pada kategori Help dan documentation terdapat 3 item, kategori Learnability terdapat 2 item, kategori Learning through the LMS terdapat 5 item, dan kategori Flexibility terdapat 6 item yang ditemukan oleh responden. Menurut Nakamura et al. (2018), permasalah yang ditemui oleh responden untuk pertama kali adalah wajar, karena responden dihadapkan pada hal yang baru dan belum pernah mereka gunakan, sehigga perlu waktu untuk mempelajarinya. Pada kaedahnya aspek pedagogical usability merupakan aspek yang mendukung LMS pada bagian jenis bahan belajar yang penggunakan akan gunakan, dengan kata lain, aspek ini merupakan isi dan fitur yang ada pada LMS untuk bisa digunakan oleh pengguna dalam meraih apa yang diharapkan. Fungsi-fungsi yang ada pada LMS wajib bisa memfasilitasi materi dan bahan belajar yang ada untuk proses pembelajaran. Pada hasil kuesioner yang diberikan kepada pengguna, bahwa LMS GC dan Quizizz memberikan suatu yang yang baru dan efisien dalam hal pengumpulan tugas, penggunakan juga memberikan pendapat bahwa saat menggunakan LMS ada unsur inovatif yang dilakukan pengajar dalam proses pembelajaran.

Pada aspek pengalaman pengguna terhadap GC dan Quizizz mengindikasikan tiga kategori yaitu kreatif, inovatif dan tidak memenuhi ekspektasi, kategori yang dihasilkan didukung juga oleh aspek general usability dan pedagogical usability. GC dan Quizizz pada aspek general usability memberikan hasil tidak memenuhi espektasi penggunanya, sesuai dengan hasil analisis terkait dengan aspek general usability LMS GC masih belum ada kolom pencarian, petunjuk, pesan kesalahan dan pilihan untuk keluar dari halaman LMS, disamping itu penggunaan GC memberikan inovasi kepada peserta didik untuk belajar melalui LMS, sehingga dapat memberikan penglaman belajar secara online yang terstruktur. Penggunaan GC juga memberikan kreatifitas kepada peserta didik untuk menjawab tugas-tugas yang diberikan lewat LMS GC, sehingga memberikan ragam tanggapan dari peserta didik.

Penggunaan GC dan Quizizz dilihat dari aspek pedagogical usability, LMS GC memberikan kebermanfaatan dalam dunia pendidikan, karena sangat membantu guru/dosen memanajemen materi,tugas, presensi kehadiran dan ujian. User Experince pada suatu aplikasi/sistem merupakan tanggapan dan pandangan baik secara perorangan atau kelompok berdasarkan penggunaan aplikasi/sistem tersebut. Perangkat lunak tidak hanya dapat digunakan secara biasa, tetapi mengandung aspek kepuasan dan kesenangan saat menggunakannya untuk menyelesaikan suatu pekerjaan. Sistem akan menjadi menarik jika sistem tersebut dapat meningkatkan pengalaman dari pengunanya.

Hasil penelitian ini menjelaskan bahwa aplikasi GC dan Quizizz memberikan pengalaman baru dalam proses pembelajaran, karena mahasiswa diberikan kesempatan untuk dapat mempelajari yang baru secara terstruktur dan bersifat online. Mahasiswa juga diberikan kesempatan untuk meningkatkan inovasi dan kreatifitas dalam memberikan tanggapan terkait tugas yang diberikan, baik berupa text, video, gambar, dll. Penggunaan LMS GC dan Quizizz tepat digunakan untuk pembelajaran dengan sistem e-learning sebagai pendukung proses pembelajaran. Aplikasi/sistem secanggih apapun masih belum dapat mengantikan proses 
pembelajaran yang dilakukan secara tatap muka, karena dengan ada interaksi langsung aura dari proses pembelajaran sangat terasa dan ekspresi dari peserta didik dari suatu materi dapat dilihat secara langsung.

\section{SIMPULAN}

User experince atau pengalaman pengguna pada Learning Management System (LMS) GC dan Quizizz memberikan unsur kreatif dan inovatif kepada peserta didik dalam proses pembelajaran secara online. GC dan Quizizz memberikan pengalaman baru kepada peserta didik dalam mengatur proses pembelajaran yang diikutinya. Disamping itu, hasil analisis user experince, LMS tidak dapat memenuhi ekspetasi bagi pengguna, dikarenakan masih ada fitur pada LMS yang membingungkan bagi pengguna. Hasil penelitian dengan metode TUXEL terhadap pengalaman pengguna GC dan Quizizz didapatkan 10 pemasalahan pada aspek General Usability dan 16 Permasalahan pada aspek Pedagogical Usability.

Sesuai dengan fungsi dan manfaatnya aplikasi/sistem LMS digunakan untuk memudahkan dosen dengan mahasiswa untuk saling terhubung saat mengakses materi dan pemberian tugas secara paperless. Hal tersebut sesuai dengan hasil analisis bahwa GC dan Quizizz memberikan kreatifitas dan inovasi kepada peserta didik, tetapi masih belum mampu memenuhi ekspetasi pengguna pada proses pembelajaran secara langsung.

\section{REFERENSI}

Ekayana, A. A. G., \& Rakasiwi, A. A. R. (2019). Pengembangan Modul Pembelajaran Mata Kuliah Internet of Things. Jurnal Pendidikan Teknologi dan Kejuruan, 16(2), 159-196. https://doi.org/10.23887/jptk-undiksha.v16i2.17594

Fauzan, F., \& Arifin, F. (2019). The effectiveness of google classroom media on the students' learning outcomes of madrasah ibtidaiyah teacher education department. Al Ibtida: Jurnal Pendidikan Guru MI,6(2), 271-285. https://doi.org/10.24235/al.ibtida.snj.v6i2.5149

Maulida, U. (2020). Konsep Blended Learning Berbasis Edmodo di Era New Normal. Dirasah: Jurnal Pemikiran dan Pendidikan Dasar Islam, 3(2), 121136.

Munthe, R. D., Brata, K. C., \& Fanani, L. (2018). Analisis User Experience Aplikasi Mobile Facebook (Studi Kasus pada Mahasiswa Universitas Brawijaya). Jurnal Pengembangan Teknologi Informasi Dan Ilmu Komputer, 2(7), 2679-2688.

Nakamura, W., Oliveira, E., \& Conte, T. (2018). TUXEL: A Technique for User eXperience Evaluation in e-Learning. Anais Dos Workshops Do VII Congresso Brasileiro de Informática Na Educação (CBIE 2018), pp. 73-80. https://doi.org/10.5753/cbie.wcbie.2018.52

Nirfayanti, N., \& Nurbaeti, N. (2019). Pengaruh Media Pembelajaran Google Classroom Dalam Pembelajaran Analisis Real Terhadap Motivasi Belajar Mahasiswa. Proximal: Jurnal Penelitian Matematika dan Pendidikan Matematika, 2(1), 50-59. https://doi.org/10.30605/2615-7667.211

Nurfalah, E. (2019). Optimalisasi E-Learning berbasis Virtual Class dengan Google Classroom sebagai Media Pembelajaran Fisika. Physics Education Research Journal, 1(1), 46-55. https://doi.org/10.21580/perj.2019.1.1.3977 
Nurhayati, D., Az-zahra, H. M., \& Herlambang, A. D. (2019). Evaluasi User Experience Pada Edmodo Dan Google Classroom Menggunakan Technique for User Experience Evaluation in E-Learning (TUXEL) (Studi Pada SMKN 5 Malang). Jurnal Pengembangan Teknologi Informasi dan Ilmu Komputer, 3(4), 3771-3780.

Pradana, D. B. P., \& Harimurti, R. (2017). Pengaruh penerapan tools google classroom pada model pembelajaran project based learning terhadap hasil belajar siswa. IT-Edu: Jurnal Information Technology and Education, 2(1), 5967.

Setiyoningtyas, R., \& Kasmui. (2020). Pengembangan Quizizz-Assisted Test Berbasis Literasi Sains Pada Materi Larutan Elektrolit Nonelektrolit. Journal of Chemistry in Education, 9(2), 133-139. https://doi.org/10.1111/j.19498594.1902.tb00418.x

Siregar, M., Rokhmawati, R. I., \& Az-zahra, H. M. (2019). Evaluasi Usability dan Pengalaman Pengguna Website Zenius . net Menggunakan Metode TUXEL : A Technique for User Experience Evaluation in e-Learning. Jurnal Pengembangan Teknologi Informasi Dan Ilmu Komputer, 3(5), 5058-5067.

Su'uga, H. S. D., Ismayati, E., Agung, A. I., \& Rijanto, T. (2020). Media ELearning Berbasis Google Classroom Untuk Meningkatkan Hasil Belajar Siswa SMK. Jurnal Pendidikan Teknik Elektro, 9(3), 605-6010.

Suyanto. (2020). Desain Pembelajaran Menggunakan Teknologi Informasi dengan Pendekatan Konstruktivistik (Blended Learning). Geography Science Education Journal (GEOSEE), 1(2), 59-66.

Tarida, L., \& Indriyani, I. (2020). Pemanfaatan Google Classroom dan Video Pembelajaran berbasis Problem Solving sebagai Solusi Kegiatan Belajar Mengajar di Era Pandemi Covid-19. Saintara: Jurnal Ilmiah Ilmu-Ilmu Maritim, 5(1), 16-20. https://amn.ac.id/ojs/index.php/saintara/article/view/88

Wahyudi, W., Rufiana, I. S., \& Nurhidayah, D. A. (2020). Quizizz: Alternatif Penilaian di Masa Pandemi Covid-19. Jurnal Ilmiah Soulmath : Jurnal Edukasi Pendidikan Matematika, 8(2), 95-108. https://doi.org/10.25139/smj.v8i2.3062

Wicaksono, V. D., \& Rachmadyanti, P. (2016). Pembelajaran Blended Learning melalui Google Classroom di Sekolah Dasar. Seminar Nasional Pendidikan PGSD UMS \& HDPGSDI Wilayah Timur, pp. 513-521. 